Article

\title{
Boosting the Performance of Nano-Ni Catalysts by Palladium Doping in Flow Hydrogenation of Sulcatone
}

\author{
Ilona Goszewska ${ }^{1}$, Małgorzata Zienkiewicz-Machnik ${ }^{1}\left(\right.$, Wojciech Błachucki ${ }^{2} \mathbb{D}$, \\ Adam Kubas ${ }^{1}{ }^{\circledR}$, Damian Giziński ${ }^{1,3}$, Krzysztof Matus ${ }^{4}{ }^{\mathbb{D}}$, Kostiantyn Nikiforow ${ }^{1}$, \\ Dmytro Lisovytskiy ${ }^{1}$, Anna Śrębowata ${ }^{1} \mathbb{D}$, Jakub Szlachetko ${ }^{2}$ and Jacinto Sá ${ }^{1,5, * \mathbb{D}}$ \\ 1 Institute of Physical Chemistry, Polish Academy of Sciences, 01-224 Warsaw, Poland; \\ izielinska@ichf.edu.pl (I.G.); mzienkiewiczmachnik@ichf.edu.pl (M.Z.-M.); akubas@ichf.edu.pl (A.K.); \\ dgizinski@ichf.edu.pl (D.G.); knikiforov@ichf.edu.pl (K.N.); dlisovytskiy@ichf.edu.pl (D.L.); \\ asrebowata@ichf.edu.pl (A.Ś.) \\ 2 Institute of Nuclear Physics, Polish Academy of Sciences, Radzikowskiego 152, 31-342 Krakow, Poland; \\ wojciech.blachucki@ifj.edu.pl (W.B.); jakub.szlachetko@ifj.edu.pl (J.S.) \\ 3 Institute of Materials Science and Engineering, Faculty of Advanced Technology and Chemistry, \\ Military University of Technology, Kaliskiego 2 Str., 00-908 Warsaw, Poland \\ 4 Materials Research Laboratory, Silesian University of Technology, 44-100 Gliwice, Poland; \\ krzysztof.matus@polsl.pl \\ 5 Department of Chemistry-Ångström Laboratory, Uppsala University, Box 532, 75120 Uppsala, Sweden \\ * Correspondence: jacinto.sa@kemi.uu.se; Tel.: +46-18-471-6806
}

Received: 7 October 2020; Accepted: 29 October 2020; Published: 2 November 2020

check for updates

\begin{abstract}
The effect of $\mathrm{Pd}$ doping on nano-Ni catalyst hydrogenation aptitude in sulcatone (6-methyl-5-hepten-2-one) hydrogenation was investigated. Obtained results demonstrated that the addition of non-catalytic amounts of $\mathrm{Pd}$ to the surface of parent Ni catalyst improves the activity to the extent that it surpassed the activity of $2.16 \mathrm{wt} \% \mathrm{Pd}$ catalyst (model catalyst) at optimal reaction conditions in the flow hydrogenation of an unsaturated ketone. Pd doping improves hydrogen activation on the catalyst, which was found to be a rate-limiting step using kinetic isotopic measurements and theoretical calculations.
\end{abstract}

Keywords: chemoselective flow hydrogenation of unsaturated ketone; Pd-modified Ni nanocatalysts; increased activity; selectivity towards $\mathrm{C}=\mathrm{C}$ bond saturation; kinetic isotopic studies

\section{Introduction}

Catalytic processes are employed in various spheres of life, undoubtedly increasing its quality. Catalysis is involved in over $80 \%$ of all chemical reactions [1], making it a ubiquitous technology for sustainable development as well as a continuous challenge for researchers working on ways to improve it. Various hydrogenation processes are of great importance since they are routinely used in the production of bulk and fine chemicals, with special emphasis on the chemical synthesis of pharmaceutical [2-4] and high-end cosmetics [5].

An attractive group of reactants is represented by unsaturated carbonyls, which are used extensively by the food, flavor, drugs, and other fine chemicals and pharmaceutical industries [6-12]. They are usually produced from unsaturated aldehydes or ketones via the hydrogenation process, thus taking control of the process chemoselectivity of vital importance $[13,14]$. Different active metals are employed in the catalytic process depending on the target bond to be successfully hydrogenated. Traditionally, noble metal (e.g., Pt, Pd, Ru) catalysts are still widely used for hydrogenation reactions, wherein palladium and platinum-based catalysts have been the most frequently studied case in selective hydrogenation towards the preferential formation of $C=C$ hydrogenated product [15-18]. 
Increasingly, for environmental and economic reasons, there is a high demand for the earth-abundant, inexpensive metals like $\mathrm{Cu}, \mathrm{Ni}, \mathrm{Co}$, Fe. Transition metal catalysts account for several chemoselective hydrogenation processes showing them as valuable alternatives to the noble metals [19-25].

Nickel proficiency on hydrogenations was shown by Sabatier [26], for which he was awarded the noble prize in 1912. The most notable liquid-phase hydrogenation nickel catalyst is the Raney nickel catalyst [27] but several other nanosystems have been proposed [28-30]. According to Kishida et al. [31], nickel hydrogenizes ketones via a Langmuir-Hinshelwood mechanism, when the catalyst surface is fully covered with the adsorbed species of hydrogen and ketone. The rate constant and the adsorption strength of ketone were found to become larger as the increasing number of alkyl carbon atoms in the molecule.

In the case of unsaturated aldehydes and ketones, nickel exhibits high selectivity towards $\mathrm{C}=\mathrm{C}$ bond saturation [32] but relatively low reaction rates compared to Pd [33]. Nickel catalyst hydrogenation catalytic properties can be promoted by the addition of a second metal achieved via doping with a second metal. In terms of selectivity enhancement, the most common dopants are less active in the catalysis than the parent metal. Thus, this enhances selectivity related to a suppression of undesirable reactions utilizing geometric and/or electronically blocking of active sites [34,35]. Nickel activity in hydrogenation can be promoted by alloy formation with a second metal, such as Co [36] and Pd [22,37]. The enhancement obtained when doping the catalyst with Pd is rationalized on the basis of improved hydrogen activation [38], and the hypothesis that is yet to be demonstrated experimentally in liquid processes.

Currently, liquid-phase hydrogenations are carried out on large-volume batch reactors [39] that present several disadvantages, such as low atom efficiency, complicated reaction schemes, low versatility, problems with catalyst separation, and overall product quality and specificity. It is not surprising that flow catalytic hydrogenation has received renewed interest by industry and academia in the last decade [40]. Continuous flow processes in micro-reactors enable savings in chemicals (reagents and solvents) and energy consumption, reduce reaction times, improve mass transfer and process safety, simplify workflows and reaction schemes, increasing control and quality of the entire process [41]. However, continuous high-pressure flow processes require innovative solutions concerning active metal morphology, catalyst support, and reactors [42,43].

The Thalesnano company was the first to release "plug-and-play" capable of performing both homogeneous and heterogeneous hydrogenations in flow and pressure, with $\mathrm{H}_{2}$, as reductant generated via electrolysis [44]. This type of reactor paved the way for the development of novel heterogeneous hydrogenation processes that comply with the green chemistry exigencies and sustainable goals. In our research group, we have used the system not only to test the catalysts catalytic proficiencies but to modify them, using a technique called on-the-fly modification in which we can modify the surface with other metals via a chemical reduction of organometallic complexes and metal salts $[32,41,45,46]$. With respect to support, they need to have suitable nominal sizes and swelling properties that enable high-pressure flow processes. Polymeric resins with specialized functional groups are particularly suitable for this purpose $[47,48]$ and allow for the study of nanometal catalysts without support interference.

This study examines the hypothesis that hydrogen activation remains the rate-limiting step in nickel hydrogenations even when the reactions are carried in flow and high pressure. Using isotopic experiments and theoretical calculations, it was possible to confirm and establish that Pd is a suitable dopant to improve catalytic activity. The nickel parent catalyst surface was subsequently modified with small amounts of Pd via surface organometallic modification, resulting in the formation of nickel nanoparticles with Pd atoms on its surface and no alloy structures. Pd doping dramatically improved parent catalyst activity in sulcatone (6-methyl-5-hepten-2-one) flow hydrogenation to levels that adding $0.2 \mathrm{wt} \% \mathrm{Pd}$ to a $0.88 \mathrm{wt} \% \mathrm{Ni}$ catalyst even surpass the values obtained with $2.16 \mathrm{wt} \% \mathrm{Pd}$ catalyst. Most importantly, the addition of Pd did not affect the overall system selectivity that remained $100 \%$ to 6-methyl-2-heptanone, confirming $\mathrm{Ni}$ appetency for the $\mathrm{C}=\mathrm{C}$ bond. It should be mentioned that the 
6-methyl-2-heptanone is a strategic intermediate in the production of vitamin E [49]. The catalysts were found to be stable under optimal reaction conditions, showing their potential for high-pressure liquid-phase flow reactions, which to the best of our knowledge, is the first of its kind.

\section{Results and Discussion}

\subsection{Characterization of the Ni Catalysts}

High-pressure liquid flow reactions put several constraints to the selection of the support, namely the support much have a suitable nominal size to prevent clogging, structural stability to sustain high pressure and temperature, and controllable swelling properties to ensure the best compromise between wetting of the catalyst sites and smooth flow. In this study, the amino group terminated polymeric resin (TentaGel-S-NH $\mathrm{N}_{2}$ ) was used. The resin swelled from $131 \mu \mathrm{m}$ to $193 \mu \mathrm{m}$ in ethanol (Figure 1), remaining within the tolerance levels of the microreactor $(100-250 \mu \mathrm{m})$ for smooth solvent flow.

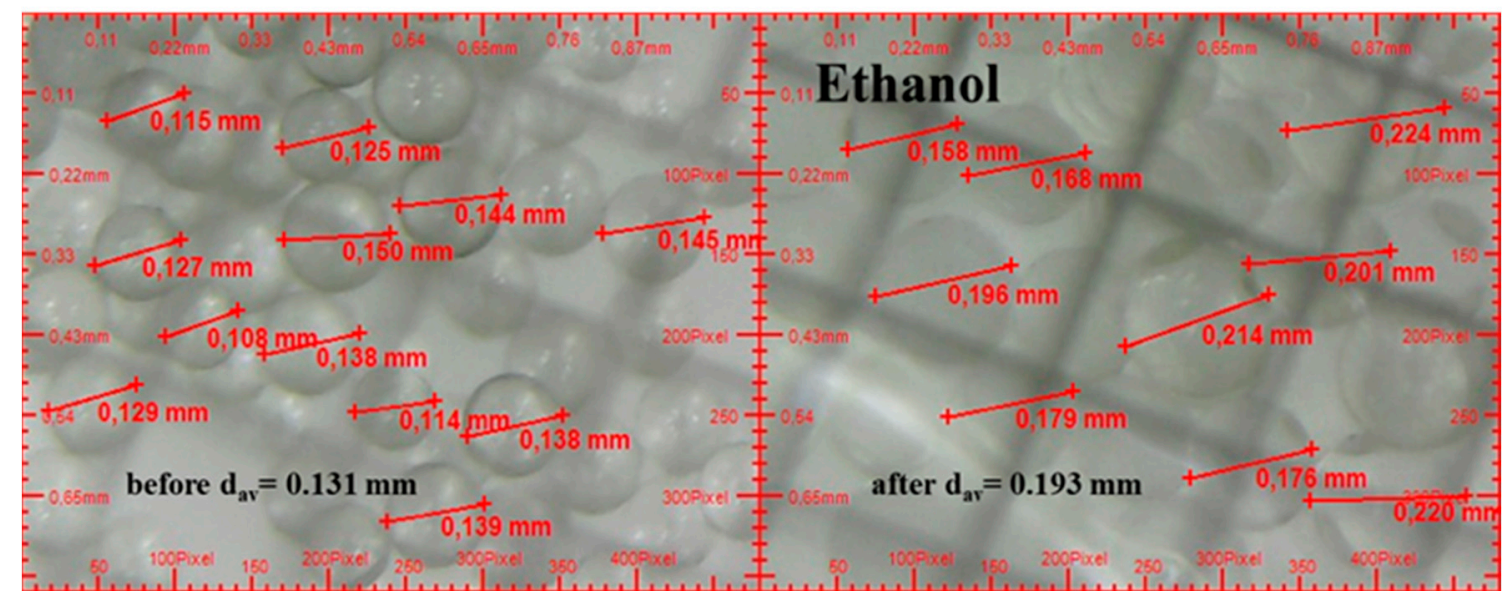

Figure 1. Optical microscopic image of $\mathrm{TNSH}_{2}$ swelling in ethanolbefore and after swelling in ethanol.

The average size of the nickel nanoparticles (Ni NPs) on the resin was estimated by transmission electron microscopy (TEM) and found to be between $3 \mathrm{~nm}$ and $5 \mathrm{~nm}$. The average size was estimated using the diameter from about 100 different particles (Figure 2a insert shows the Ni NPs size distribution histogram). High-angle annular dark-field scanning transmission electron microscopy (HAADF-TEM) (Figure 2b) shows well-distributed metal particles throughout the polymer bead. The nickel loading was found to be ca. $0.86 \mathrm{wt} \%$, determined by atomic absorption spectrosmetry (AAS). The addition of the Ni NPs to the resin did not affect its structure at least in a detectable way (see supporting information (SI) powder X-ray diffraction (XRD) measurements Figure S1). 
a)

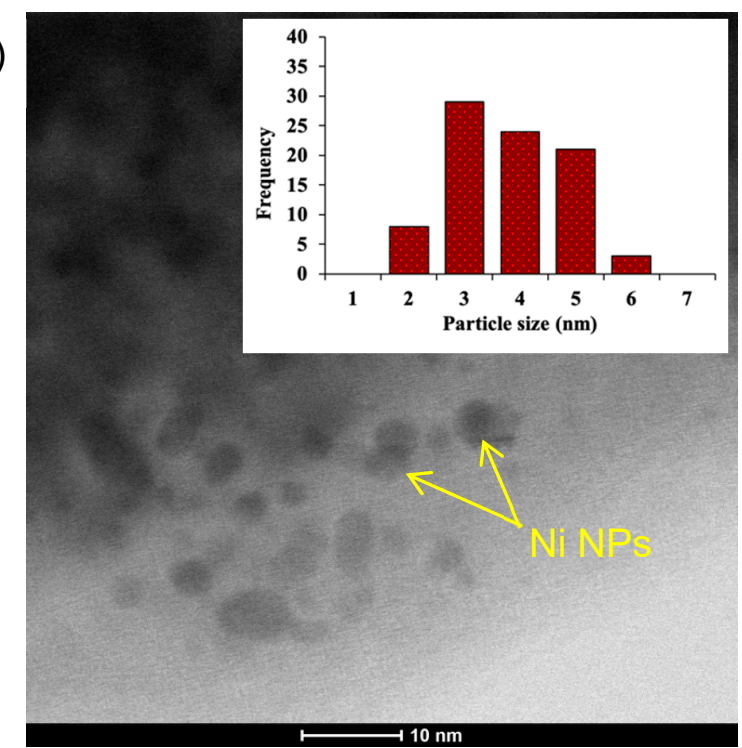

b)

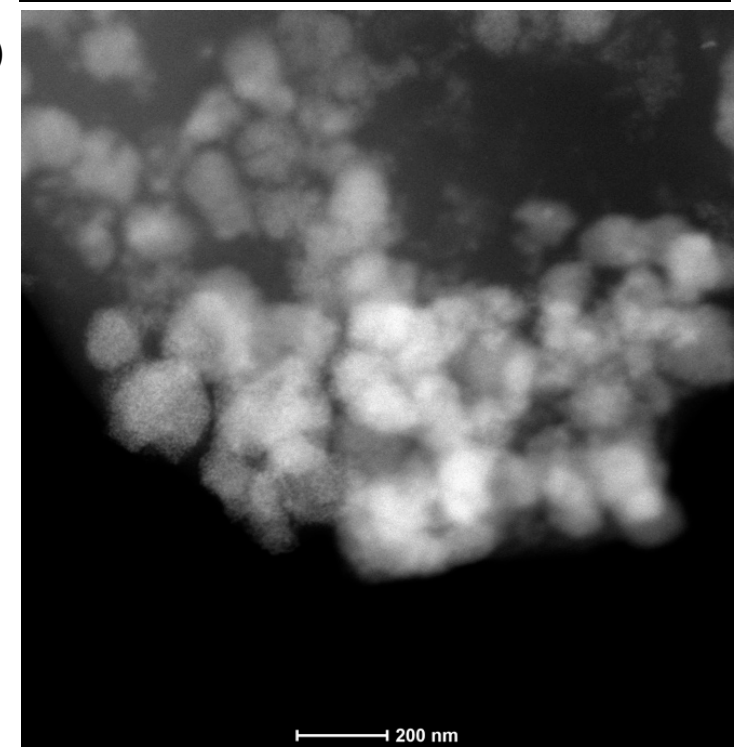

Figure 2. Transmission electron microscopy images of $\mathrm{NiTSNH}_{2}$ catalyst. (a) TEM micrograph with particle size distribution histogram (insert) and (b) HAADF-TEM.

Fourier-transform infrared spectroscopy (FT-IR) measurements were performed to evaluate the changes to the primary amine groups after adding Ni NPs to the TentaGel-S-NH $\mathrm{N}_{2}$ and confirm this as the preferential binding site of the Ni NPs. FTIR spectrum presented in Figure S2 shows the primary amine $-\mathrm{NH}$ stretching $\left(3200-3800 \mathrm{~cm}^{-1}\right)$ and bending $\left(1550-1700 \mathrm{~cm}^{-1}\right)$ regions. Bands centred at 3470 and $1650 \mathrm{~cm}^{-1}$ are ascribed to primary amines on the $\mathrm{TSNH}_{2}$. Upon inclusion of the Ni NPs, the bands decrease in intensity corroborating that Ni NPs bond to the polymer via the amino functionalities (Figure S2), as reported previously [50].

\subsection{Isotopic Experiments}

Transition metals, such as $\mathrm{Cu}, \mathrm{Fe}$, and $\mathrm{Ni}$, have moderate activities in liquid phase catalysis [51,52], which hinders the application in flow processes. The most established hypothesis for transition metals modest activity is their lower aptitude to activate hydrogen. A direct way to evaluate this hypothesis is to perform isotopic hydrogenations with deuterium as a reducing agent. To our knowledge, this is one of the first studies where isotopic experiments were performed in high-pressure liquid-phase hydrogenations. Figure 3 shows the average catalytic activity in the conversion of 
6-methyl-5-hepten-2-one at different temperatures and 60 bar gas $\left(\mathrm{H}_{2}\right.$ or $\left.\mathrm{D}_{2}\right)$ pressure at constant reactant flow and concentration. Temperature and gas pressure controlled the surface reactant ratios, which regulate the catalytic activity. It is worth mentioning that in the Thalesnano 'plug-and-play' used in this study, hydrogen is generated from water electrolysis, and thus deuterium can be equally generated when heavy water $\left(\mathrm{D}_{2} \mathrm{O}\right)$ is used instead, enabling direct comparison of catalytic performance. It is clear from Figure 3 that reactions in deuterium show considerably lower activity than in hydrogen, independently of the temperature. Similar behavior was also observed for studies under variable pressure. We used those catalytic studies to estimate the average kinetic isotopic effect (KIE). The average KIE is defined as the activity ratio between light and heavy isotopic ranges [53], which are summarized in Table 1. Despite the variability, KIE extracted are all above 1.7 , except for reaction at $45^{\circ} \mathrm{C}$, which verifies the hypothesis that hydrogen activation is the rate-limiting step in high-pressure liquid-phase hydrogenations with nickel, which was further corroborated by density functional theory (DFT) calculations. The process is $100 \%$ selective to 6-methyl-2-heptanone formation (semihydrogenation with $\mathrm{C}=\mathrm{C}$ bond saturation), which remains when $\mathrm{D}_{2}$ is used instead of $\mathrm{H}_{2}$, meaning deuteration affects only the reductant activation rate, not the reaction mechanism. The deuterated form of the product was confirmed by the disappearance of the signal from protons of the pseudo isopropyl group $\left(\mathrm{CH}_{3}-\mathrm{CH}_{3}\right)$ in the nuclear magnetic resonance (NMR) spectra (NMR Figures S3 and S4). Note that the isotopic catalytic tests were performed with the same catalyst, and the activity could be cycled upon changing the reductant gas. Additionally, $\mathrm{Ni}$ average particle size before and after the catalysis was the same. Thus, the presented changes in activity due to the gaseous isotope are solely related to the ability to activate hydrogen, not surface modification and/or different exposed metal surface area.

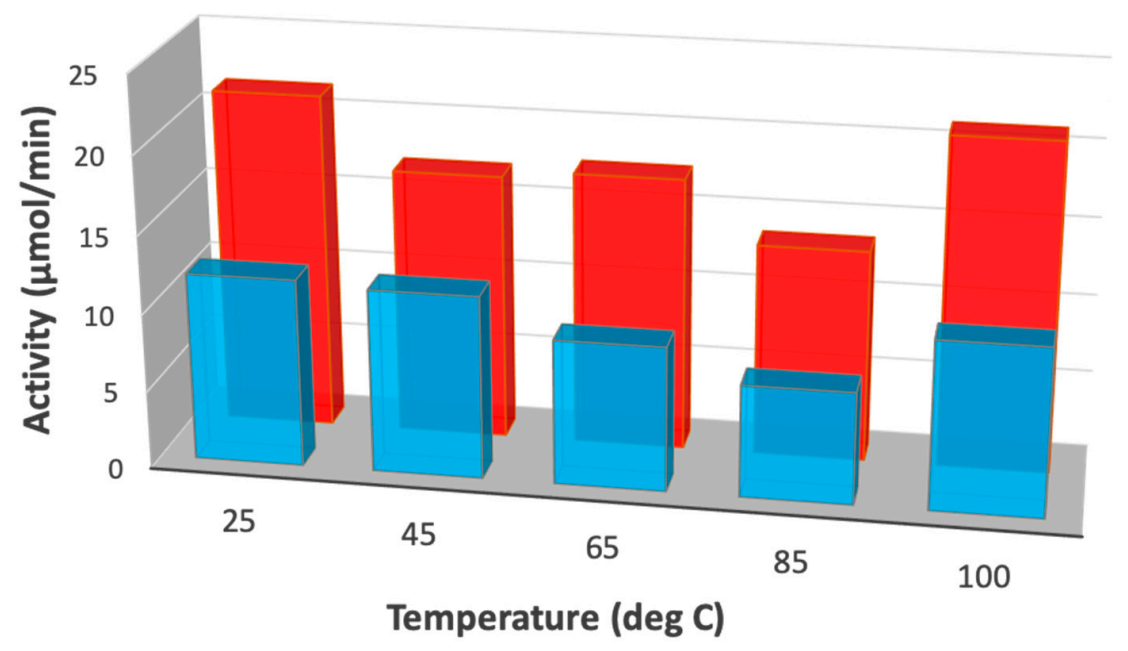

Figure 3. Average catalytic activity for $\mathrm{NiTSNH}_{2}$ in the conversion of 6-methyl-5-hepten-2-one at different temperatures and gas $\left(\mathrm{H}_{2}\right.$-red or $\mathrm{D}_{2}$-blue $)$ pressures with a reactant flow rate of $0.5 \mathrm{~mL} / \mathrm{min}$ and 60 bar.

Table 1. Average KIE as a function of temperature and gaseous reductant pressure.

\begin{tabular}{cccc}
\hline Temperature $\left({ }^{\circ} \mathbf{C}\right)$ & KIE & Gas Pressure (Bar) & KIE \\
\hline 25 & $1.81 \pm 0.38$ & 10 & $1.96 \pm 0.78$ \\
45 & $1.29 \pm 0.16$ & 20 & $1.72 \pm 0.18$ \\
85 & $1.96 \pm 0.05$ & 40 & $1.71 \pm 0.39$ \\
100 & $2.11 \pm 0.55$ & 60 & $1.79 \pm 0.20$ \\
\hline
\end{tabular}

Activity is an interplay between reactants surface coverage, reactants adsorption energy, and product desorption. This is rather complicated to track in such a complicated system, but the fact that-independent of gas pressure and temperature used-there is a clear kinetic isotopic effect 
(KIE) between 1.7-2.0, validates that hydrogen activation as the rate-limiting step and this cannot be overcome by manipulation of reactions conditions. Therefore, to improve nickel catalysts activity in flow hydrogenation, one must modify the catalyst, so the hydrogen activation step is promoted. A logical step would be to dope the nickel with a metal that can activate hydrogen effortlessly, with palladium being a preferred candidate due to its strong hydrogen affinity [54].

\subsection{DFT Calculations}

DFT calculations were performed to assess if Pd is a suitable candidate to improve Ni parent catalyst activity by promoting $\mathrm{H}_{2}$ activation reaction,. The calculations establish the energy associated with various steps in hydrogen activation for $\mathrm{Ni}$ and $\mathrm{Pd}$ (Table 2), as well as to a nickel-palladium bimetallic system containing $7.6 \%$ of $\mathrm{Pd}\left(\mathrm{Ni}_{13} \mathrm{Pd}\right)$. As expected, we found a higher affinity of $\mathrm{H}_{2}$ to $\mathrm{Pd}$ nanoparticles as compared to Ni nanoparticles (binding energies of -4.7 and $-2.0 \mathrm{kcal} / \mathrm{mol}$, respectively). Interestingly, model bimetallic nanoparticle displays enhanced binding affinity $(-6.7 \mathrm{kcal} / \mathrm{mol})$. Nickel has significantly lower $\mathrm{H}_{2}$ dissociation energy $(-10.4 \mathrm{kcal} / \mathrm{mol})$ as compared to palladium $(-29.2 \mathrm{kcal} / \mathrm{mol})$. $\mathrm{Ni}_{13} \mathrm{Pd}$ model is somewhere in between with the hydrogen preferentially binding to $\mathrm{Pd}$ site with energetic effect of about $25 \mathrm{kcal} / \mathrm{mol}$. Accordingly, we found a more than three times lower

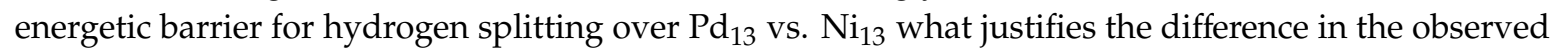
average conversion of 6-methyl-5-hepten-2-one. Additionally, by replacing $\mathrm{H}_{2}$ with $\mathrm{D}_{2}$, one increases the dissociation barrier by about $0.5 \mathrm{kcal} / \mathrm{mol}$. Such an increase should show up in decreased activity when using heavier isotope. The calculations also suggest that the Ni deficiency in activating molecular hydrogen could be suppressed with the addition of small amounts of Pd.

Table 2. Calculated energetic effects of hydrogen binding to the model metal nanoparticles $\left(\mathrm{Ni}_{13}, \mathrm{Pd}_{13}\right.$, and $\mathrm{Ni}_{13} \mathrm{Pd}$ ) and $\mathrm{H}_{2}$ dissociation at the surface of the nanoparticles. For the latter, the transition state (TS) energy for the deuterium-substituted system is provided in parenthesis. All reported energies are in $\mathrm{kcal} / \mathrm{mol}$ and are corrected for zero-point energy change (ZPE).

\begin{tabular}{cccc}
\hline & $\mathbf{N i}_{\mathbf{1 3}}$ & $\mathbf{P d}_{\mathbf{1 3}}$ & $\mathbf{N i}_{\mathbf{1 3}} \mathbf{P d}$ \\
\hline $\begin{array}{c}\mathrm{H}_{2} \text { binding } \\
{\left[\mathrm{H}_{2}+\mathrm{M} \rightarrow \mathrm{M}\left(\mathrm{H}_{2}\right)\right]}\end{array}$ & -2.0 & -4.7 & -6.7 \\
\hline $\begin{array}{c}\mathrm{H}_{2} \text { dissociation TS } \\
{\left[\mathrm{M}\left(\mathrm{H}_{2}\right) \rightarrow \mathrm{M}\left(\mathrm{H}_{2}\right)^{\ddagger}\right]^{*}}\end{array}$ & $6.7(7.0)$ & $1.7(2.2)$ & $2.6(3.1)$ \\
\hline $\begin{array}{c}\mathrm{H}_{2} \text { dissociation } \\
{\left[\mathrm{M}\left(\mathrm{H}_{2}\right) \rightarrow \mathrm{M}(2 \mathrm{H})\right]}\end{array}$ & -8.5 & -24.6 & -18.2 \\
\hline $\begin{array}{c}\text { overall } \\
{\left[\mathrm{H}_{2}+\mathrm{M} \rightarrow \mathrm{M}(2 \mathrm{H})\right]}\end{array}$ & -10.4 & -29.2 & -24.9 \\
\hline
\end{tabular}

* In parenthesis data for $\mathrm{M}\left(\mathrm{D}_{2}\right) \rightarrow \mathrm{M}\left(\mathrm{D}_{2}\right)^{\ddagger}$.

\subsection{Characterization of Pd-Modified Catalysts}

Building on the KIE results and DFT calculations, one way to improve nickel catalytic activity is to add a second metal, more specifically palladium. Utilizing surface modification chemistry methodology, two nickel modified catalysts with sub-catalytic amounts of palladium were prepared. The metal loading and efficiency of the method used to deposited Pd are summarized in Table 3. The Pd concentrations were kept purposively low, so the catalytic activity is primarily governed by Ni surface. 
Table 3. Ni and Pd content in the monometallic and bimetallic catalysts

\begin{tabular}{ccccc}
\hline Sample & Ni wt\% & Pd wt\% & Pd/Ni Ratio & $\begin{array}{c}\text { Pd Deposition } \\
\text { Efficacy (\%) }\end{array}$ \\
\hline $\mathrm{NiTSNH}_{2}$ & $0.86 \pm 0.03$ & - & - & - \\
$\mathrm{PdTSNH}_{2}$ & - & $2.16 \pm 0.13$ & - & - \\
$\mathrm{NiPd}_{0.05} \mathrm{TSNH}_{2}$ & $0.85 \pm 0.03$ & $0.08 \pm 0.03$ & 0.05 & 70 \\
$\mathrm{NiPd}_{0.13} \mathrm{TSNH}_{2}$ & $0.88 \pm 0.04$ & $0.20 \pm 0.02$ & 0.13 & 88 \\
\hline
\end{tabular}

The location of Pd in respect to Ni was assessed by STEM with EDS analysis (Figure 4). STEM images, together with elemental mapping, revealed that the large majority of the metals nanoparticles in all catalysts are spherical and well-dispersed nanoparticles and that Pd is only found in the vicinity of Ni. HRTEM images (Figure 5) show the co-existence of Ni and Pd lattice spacings. Additionally, there was no significant increase in the Ni nanoparticles size after Pd doping, suggesting no alloy formation. Based on the microscopy observations, one can infer that the methodology used ensures decoration of nickel surface by palladium atoms, similar to previous reports [34,35].
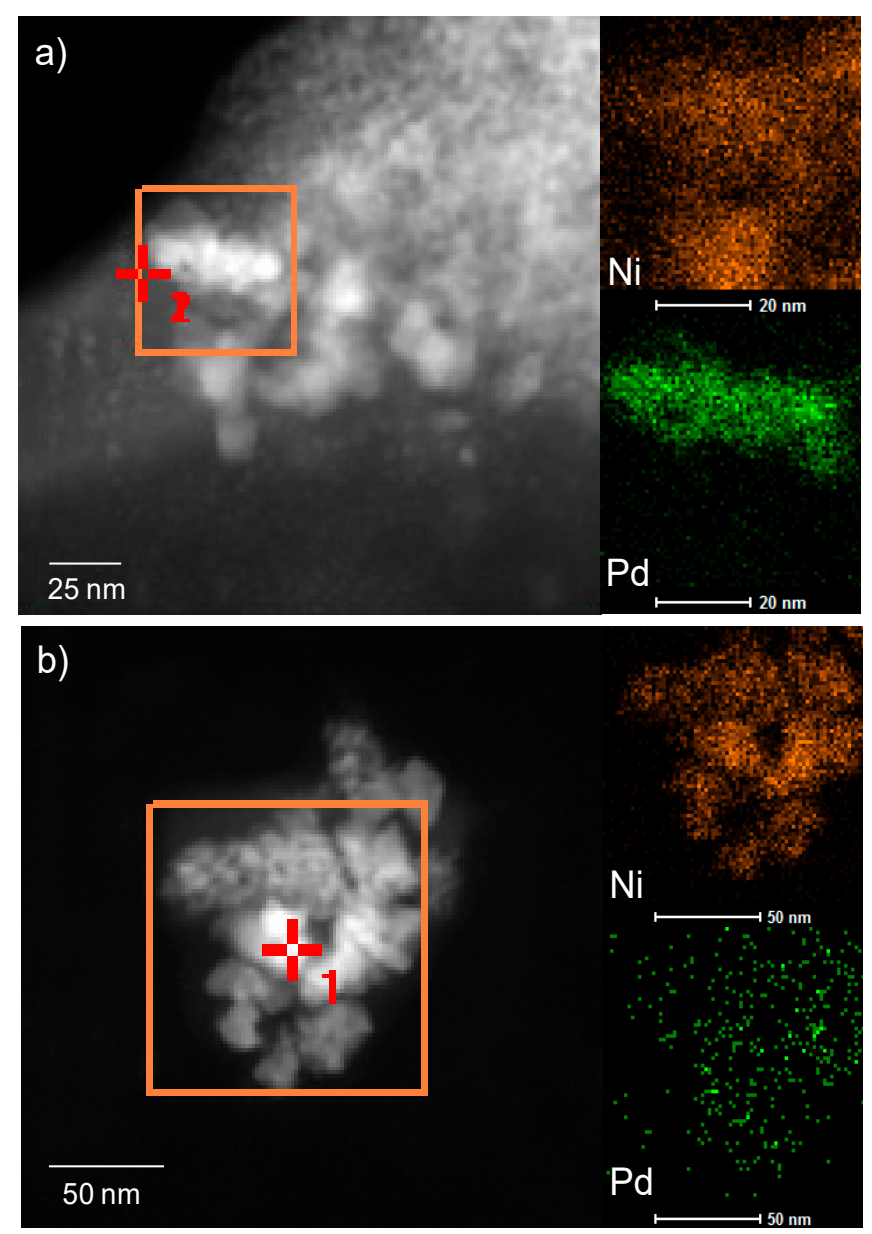

Figure 4. STEM images and elemental mapping for (a) $\mathrm{NiPd}_{0.05} \mathrm{TSNH}_{2}$ and (b) $\mathrm{NiPd}_{0.13} \mathrm{TSNH}_{2}$. 

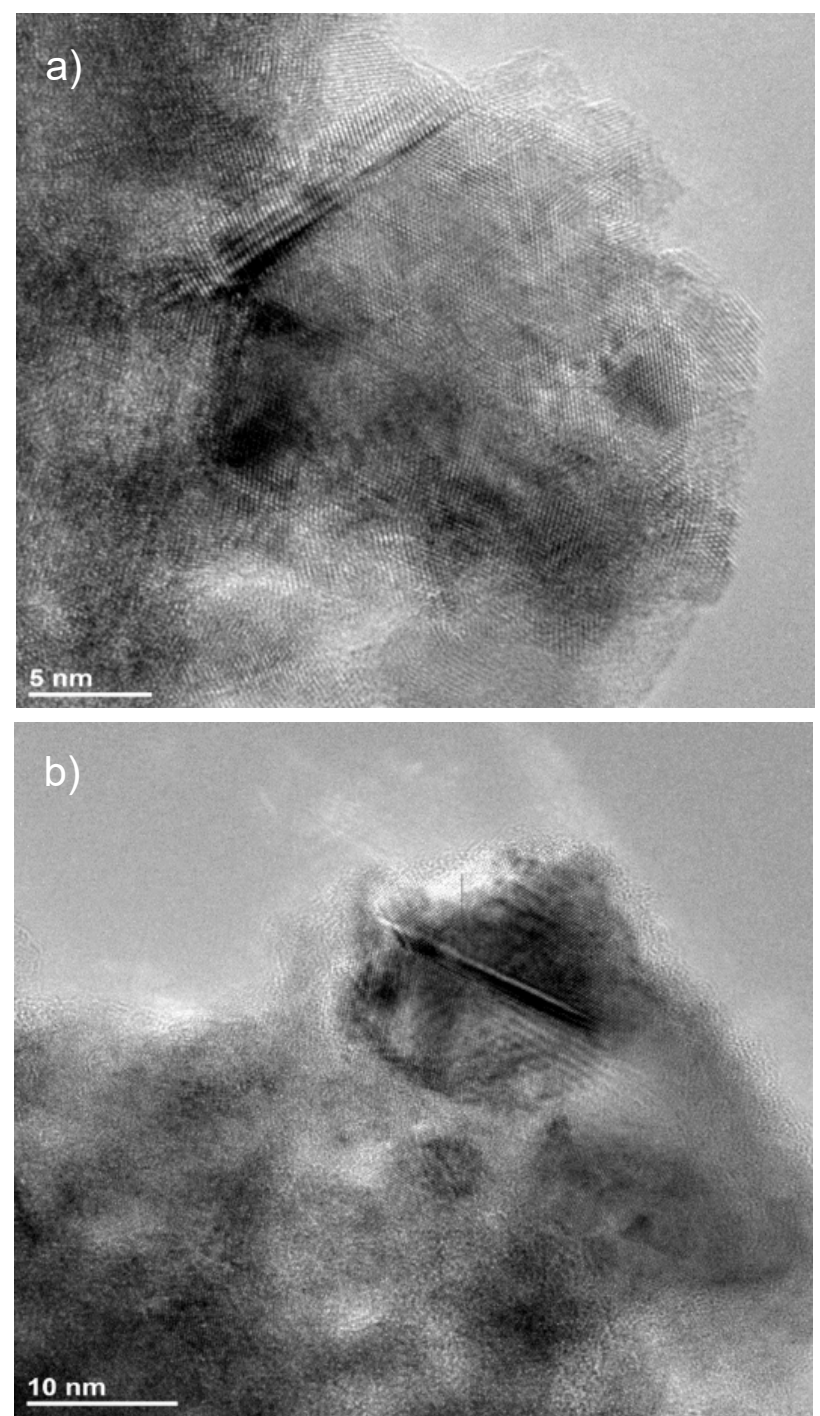

Figure 5. HRTEM images of Pd-modified Ni catalysts for (a) $\mathrm{NiPd}_{0.05} \mathrm{TSNH}_{2}$ and (b) $\mathrm{NiPd}_{0.13} \mathrm{TSNH}_{2}$.

X-ray absorption spectroscopy at the Ni K-edge was performed to assess the electronic structure of the $\mathrm{Ni}$ after $\mathrm{Pd}$ addition. The experiments were performed on recently commission laboratory setup instead of synchrotron as per norm. Ni K-edge X-ray absorption spectroscopy (XAS) spectra for the samples Pd-modified $\mathrm{NiTSNH}_{2}$ are presented in Figure 6. The X-ray absorption near-edge structures (XANES) observed in the two measured spectra differ, but both unveil the presence of $\mathrm{Ni}$ atoms with different oxidation states. To extract the relative populations of $\mathrm{Ni}$ oxidation states, the obtained spectra were fitted with a linear combination of $\mathrm{Ni}^{0}, \mathrm{Ni}^{2+}$, and $\mathrm{Ni}^{3+}$ using XAS reference spectra of $\mathrm{Ni}$ foil, $\mathrm{NiO}$, and $\mathrm{Ni}_{2} \mathrm{O}_{3}$, respectively [55]. The fitting results indicate the presence of $\mathrm{Ni}^{0}$ and $\mathrm{Ni}^{3+}$ species in the samples and the absence of $\mathrm{Ni}^{2+}$ (Table 4). It should be noted that the introduction of $\mathrm{Pd}$ to the monometallic catalyst resulted in a partially reduced of $\mathrm{Ni}^{3+}$ form. Our previous studies over Ni-based catalysts suggest that $\mathrm{Ni}^{3+}$ form is located primarily on the surface and is the result of surface passivation by contact with atmospheric air [21], which is expected to be reduced (partially or completely) during the conditioning of the catalysts before the catalytic tests. 

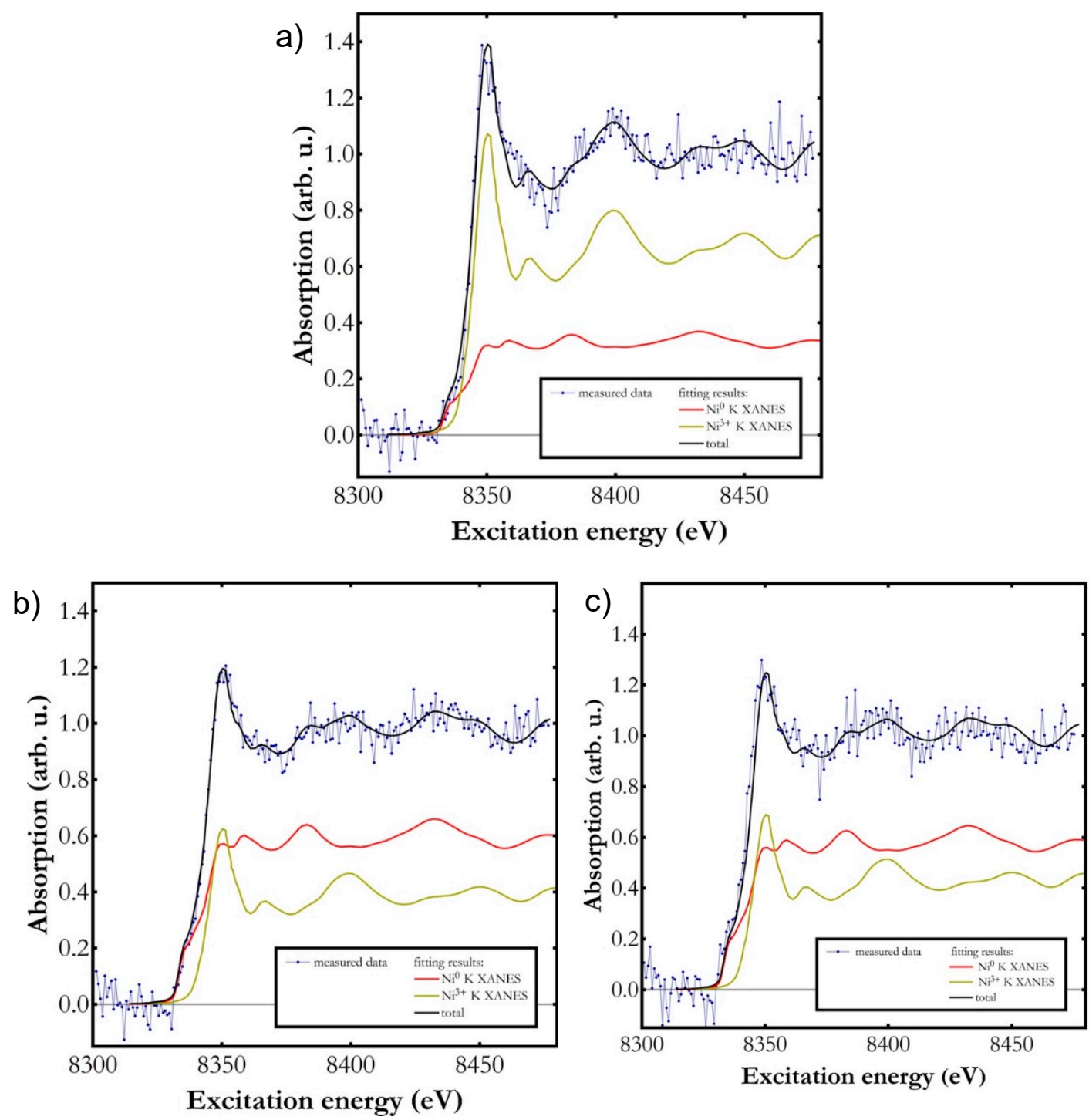

Figure 6. $\mathrm{Ni} \mathrm{K}$ X-ray absorption spectrum measured for (a) $\mathrm{NiTSNH}_{2} ;$ (b) $\mathrm{NiPd}_{0.05} \mathrm{TSNH}_{2}$; and $(\mathbf{c}) \mathrm{NiPd}_{0.13} \mathrm{TSNH}_{2}$. The solid lines present the best fit of a linear combination of $\mathrm{Ni}^{0}$ and $\mathrm{Ni}^{3+}$ reference XAS spectra to the measured data.

Table 4. Contribution of $\mathrm{Ni}^{0}$ and $\mathrm{Ni}^{3+}$ species extracted from Ni K-edge XAS spectra.

\begin{tabular}{ccc}
\hline Sample & $\mathbf{N i}^{\mathbf{0}} \mathbf{( \% )}$ & $\mathbf{N i}^{\mathbf{3}} \mathbf{( \% )}$ \\
\hline $\mathrm{NiTSNH}_{2}$ & $34 \pm 2.0$ & $66 \pm 2.0$ \\
$\mathrm{NiPd}_{0.05} \mathrm{TSNH}_{2}$ & $61 \pm 1.5$ & $39 \pm 1.5$ \\
$\mathrm{NiPd}_{0.13} \mathrm{TSNH}_{2}$ & $58 \pm 2.2$ & $42 \pm 2.2$ \\
\hline
\end{tabular}

XPS analysis was performed to establish the oxidation state of Pd. Due to the low amounts of Pd in the samples, accurate assignment of the peaks was not possible. Therefore, a catalyst with a higher amount of Pd (Table S1) was prepared that showed similar microscopy (Figures S5 and S6). XPS analysis showed a single dominant signal of $\mathrm{Pd} 3 \mathrm{~d}_{5 / 2}$ is located at $335.5 \mathrm{eV}$, corresponding to metallic palladium [56,57].

\subsection{Catalytic Activity of Ni and Pd-Modified Catalysts in Flow Hydrogenation}

To validate the hypothesis that Ni hydrogenation activity could be improved with the addition of sub-catalytic amounts of Pd to its surface, catalytic tests were performed using 6-methyl-5-hepten-2-one 
as a model reaction. Apart from the commercial importance, the reaction allows us to assess simultaneously the impact of Pd in both activity and selectivity since it has two hydrogenate sites (see Scheme 1). The experiments were performed in continuous-flow as aforementioned. Catalytic tests were carried out in a wide range of temperatures and pressures to optimize reaction parameters (SI Figures S7 and S8). Note that changes in temperature and pressure affect the overall reactivity and performance by changing the species surface concentration and ration, making difficult the correlation of activity data under different experimental conditions. Therefore, we opted for conditions where the role of Pd addition could be unequivocally demonstrated, namely $10{ }^{\circ} \mathrm{C}$ and 40 bar with $0.5 \mathrm{~mL} / \mathrm{min}$ flow rate of $0.5 \mathrm{M}$ reactant (Figure 7). The results were compared with respect to $\mathrm{PdTSN}_{2}$ that exhibit the best perfomace at 10 bar hydrogen and $85^{\circ} \mathrm{C}$. The experiments were performed over $5 \mathrm{~h}$ to assess catalytic stability and provide confidence in the results.

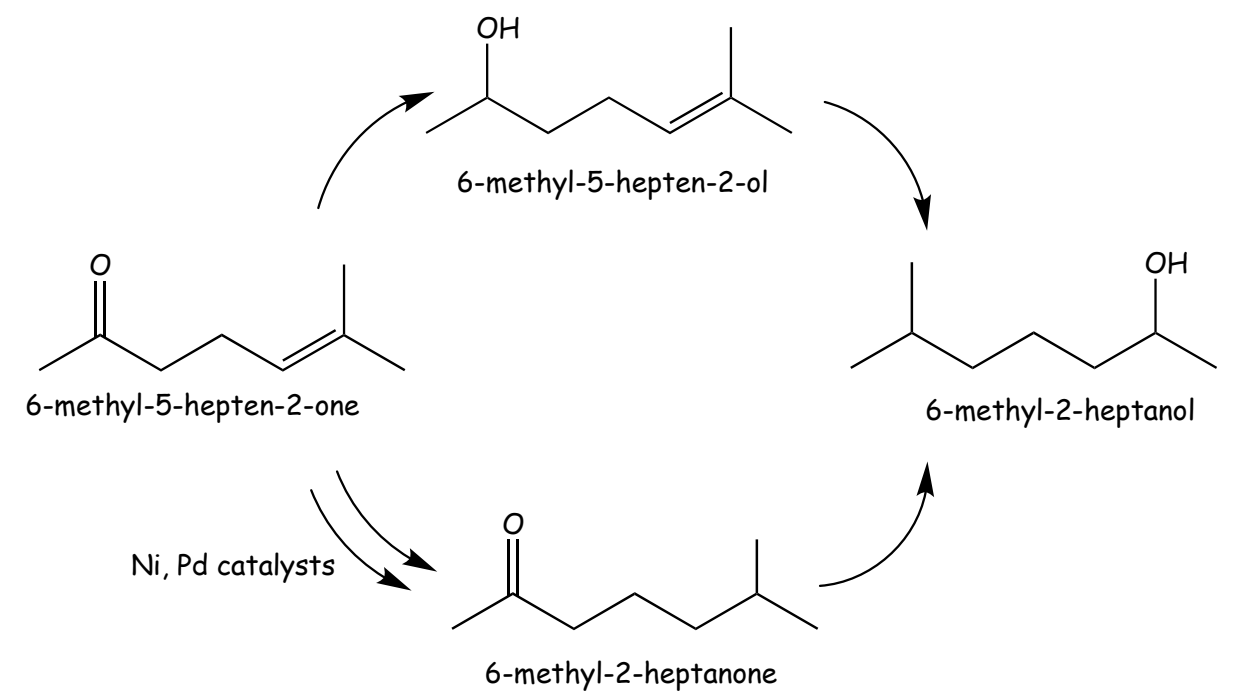

Scheme 1. Possible reaction pathways for 6-methyl-5-hepten-2-one hydrogenation.

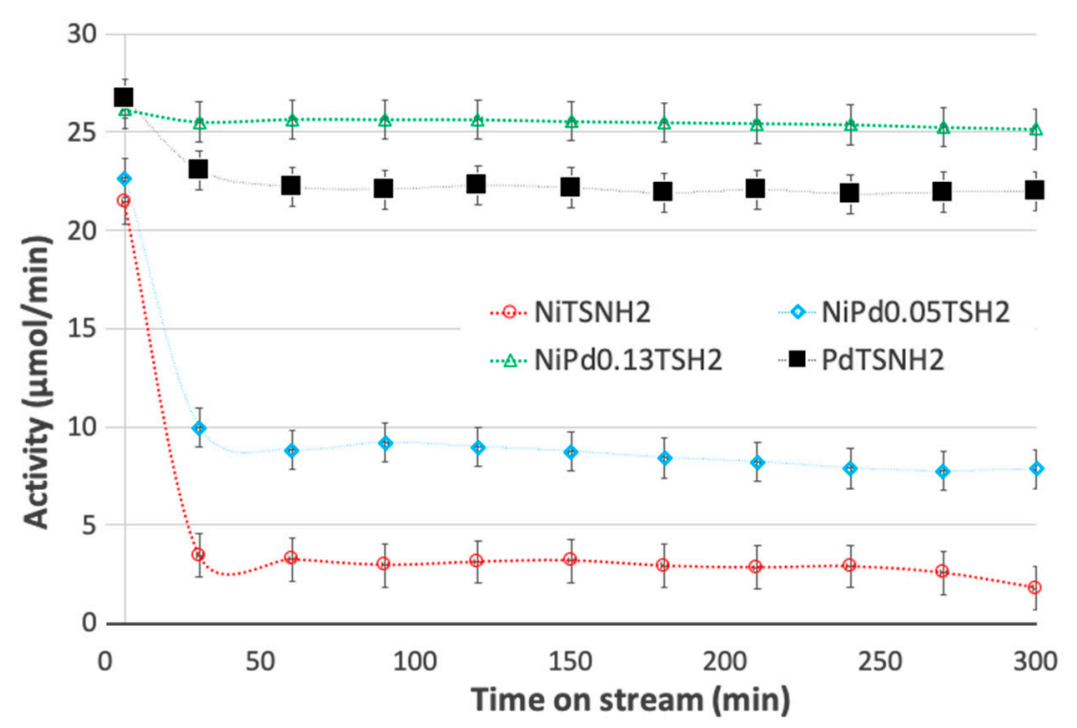

Figure 7. Catalytic activity in the conversion of $0.05 \mathrm{M}$ 6-methyl-5-hepten-2-one at $100{ }^{\circ} \mathrm{C}$ and 40 bar of hydrogen with a reactant flow rate of $0.5 \mathrm{~mL} / \mathrm{min}(25 \mu \mathrm{mol} / \mathrm{min})$, except for $\mathrm{PdTSNH}_{2}$ that was tested under optimal conditons, namely 10 bar hydrogen and $85^{\circ} \mathrm{C}$.

From the activity studies (Figure 7), it is possible to see that the monometallic Pd catalyst is considerably more active than its Ni counterpart. Pd had an average activity of $22 \mu \mathrm{mol} / \mathrm{min}$ compared to $\sim 3 \mu \mathrm{mol} / \mathrm{min}$ for the $\mathrm{Ni}$ at optimal conditions. Even after normalization to meal content, 
$\mathrm{Pd}$ activity is three-fold higher than the one of $\mathrm{Ni}$. In both cases, the only detected product was 6-methyl-2-heptanone related to the semihydrogenation with $\mathrm{C}=\mathrm{C}$ bond saturation, with nearly perfect carbon balanced achieved. This is important since it allows direct comparison of the catalysts because they only affect the rate of reaction not the reaction mechanism. Additionally, after the steady-state conditions were attained (20-30 min after starting the reaction), both activity and selectivity values were found to be stable, suggesting that catalysts are stable under our reaction conditions.

Surface modification of $\mathrm{Ni}$ with $\mathrm{Pd}$ dramatically changed the activity of the parent catalyst (Figure 7), without affecting its stability and selectivity that remains $100 \%$ to 6-methyl-2-heptanone. Even a very small addition of $\mathrm{Pd}$, such as with the case of $\mathrm{NiPd}_{0.05} \mathrm{TSNH}_{2}$, dramatically increased the activity by nearly three-fold compared to the parent nickel catalyst. Even more surprising is the activity result attained with the $\mathrm{NiPd}_{0.13} \mathrm{TSNH}_{2}$ catalyst, which surpassed the activity of the monometallic Pd by ca. $3.5 \mu \mathrm{mol} / \mathrm{min}$, which is relevant since Pd is considered the best hydrogenation catalyst, and we use roughly twice more Pd than the total metal content in our best performing catalyst. In fact, after normalization of metal content, $\mathrm{NiPd}_{0.13} \mathrm{TSNH}_{2}$ was found to be about 2.3 times more active than the monometallic Pd, at optimal conditions. The observations can be easily understood by a significant increase in hydrogen activation due to the addition of palladium. Further increase of Pd amount led to only smaller improvement in the catalysis (Figure S9), however at such Pd concentration $(0.22 \mathrm{wt} \%)$ we cannot discard the possibility for catalysis on Pd solely. The proposed mechanism is that Pd activates the hydrogen and readily spills it over to the Ni sites, where the $C=C$ double bond is easily hydrogenated [58] at a faster than on a Pd counterpart possible due to selective absorption of the substrate. Note that the amount of Pd added to the nickel is too low to be considered catalytically active, i.e., when the reaction is performed with such small amounts of Pd no products were detected. Finally, it is worth mention that long stability measurements are out of the scope of the manuscript. However, considering known issues surrounding Ni catalysts' stability on stream, the catalysts were tested over $24 \mathrm{~h}$, where little to no degradation of their activity was observed. While this is not indicative of long-term stability, it corroborates the findings that adding Pd promotes catalyst activity well beyond the initial stages of the reaction.

\section{Experimental Section}

Analytical grade organic salts, polymeric resin, and solvents were used as received without further purification. The chemicals were purchase from Sigma-Aldrich (Poznan, Poland) except the resin that was purchased from Rapp Polymere (Tübingen, Germany).

\subsection{Preparation of the Catalysts}

\subsubsection{Synthesis of $\mathrm{NiTSNH}_{2}$}

Parent material $\left(\mathrm{NiTSNH}_{2}\right)$ was synthesized at ambient temperature and under an argon atmosphere in two steps, as described elsewhere [21]. Initially, Ni nanoparticles were obtained by chemical reduction of nickel (II) acetylacetonate $(0.001 \mathrm{~mol})$ with $0.01 \mathrm{~g}$ of $\mathrm{NaBH}_{4}$ (reducing agent) and $3.5 \mathrm{~g}$ of trioctylophosphine oxide (TOPO, capping agent) in $100 \mathrm{~mL}$ of ethanol. Since Ni NPs are prone to aggregation, we used tenfold excess TOPO compared to Ni in solution. After synthesis, the as-prepared Ni NPs were immobilized on amino groups terminated polymeric resin (TentaGel-S-NH $\mathrm{N}_{2}, 5 \mathrm{~g}$ ) with a pore volume of $0.13 \mathrm{~cm}^{3} / \mathrm{g}$ and bead size of $130 \mathrm{~m}$.

\subsubsection{Synthesis of $\mathrm{PdTSNH}_{2}$}

To prepare palladium nano-catalyst we adopted a similar procedure as for $\mathrm{NiTSNH}_{2}$ synthesis, which was described in detailed elsewhere [10]. Briefly, the palladium precursor $\left(\operatorname{Pd}(\mathrm{acac})_{2}\right)$ was dissolved in ethanol and mixed with $1 \mathrm{~g}$ of TOPO (capping agent). $0.03 \mathrm{~g}$ of $\mathrm{NaBH}_{4}$ (reducing agent) was added to the mixture at ambient conditions and under argon atmosphere and vigorous stirring. The prepared Pd NPs were centrifuged and purified with ethanol and hexane and finally were 
immobilized on commercially available polymeric resin TentaGel-S- $\mathrm{NH}_{2}(130 \mu \mathrm{m}$ of bead size, a pore volume of $0.13 \mathrm{~cm}^{3} / \mathrm{g}$ ). The obtained catalyst $\mathrm{PdTSNH}_{2}$ was dried at $90{ }^{\circ} \mathrm{C}$ and then used in the hydrogenation as prepared.

\subsubsection{Synthesis of Pd Modified $\mathrm{NiTSNH}_{2}$}

Palladium surface modification was carried out via a modified surface redox reaction method, described by Barbier et al. [59,60] and Sá et al. [61,62]. Scheme 2 depicts a representation of the reactor used to modify the parent Ni catalyst with Pd. As-prepared $0.5 \mathrm{~g} \mathrm{NiTSNH}{ }_{2}$ was placed in the sealed batch reactor. The catalyst was reduced at $150^{\circ} \mathrm{C}$ for $1 \mathrm{~h}$ in a stream of hydrogen and subsequently cooled to room temperature in an argon atmosphere. Once cooled, $15 \mathrm{~mL}$ of purified ethanol was introduced with a syringe, followed by $10 \mathrm{~mL}$ palladium acetylacetonate $\left(\mathrm{Pd}(\mathrm{acac})_{2}\right)$ solution in ethanol. The obtained catalyst was dried in the flow of argon (40 min) and afterwards in the flow of mixture $\mathrm{Ar}+\mathrm{H}_{2}$. The modified catalysts are labeled $\mathrm{NiPd}_{\mathrm{y}} \mathrm{TSNH}_{2}$, y being the $\mathrm{Pd}$ atomic ratio.

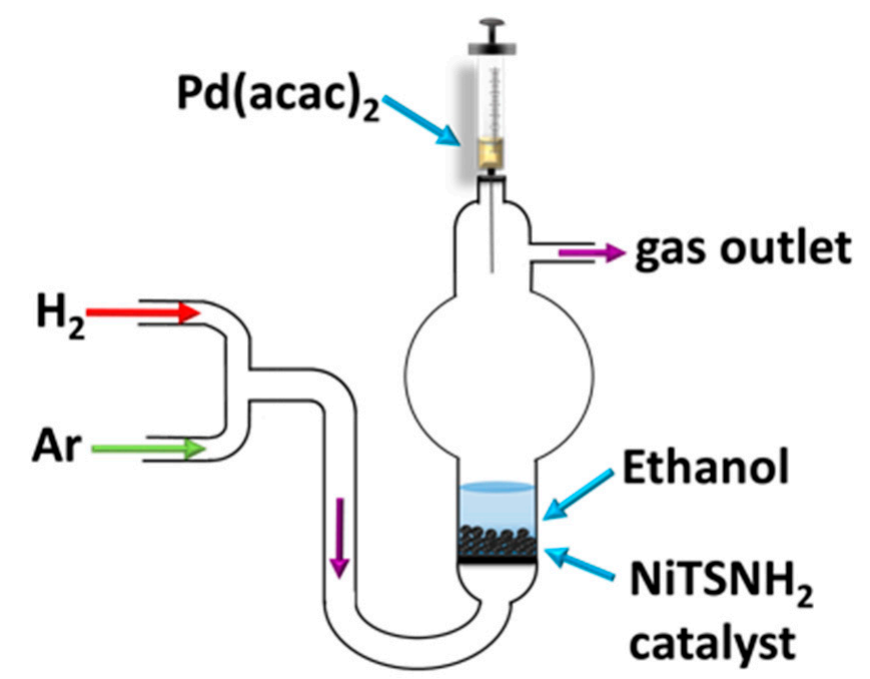

Scheme 2. Batch reactor for direct redox modification of $\mathrm{NiTSNH}_{2}$.

\subsection{Catalysts Characterization Technics}

The metals concentration in monometallic and palladium-modified nickel catalysts were determined by atomic absorption spectrometry (AAS) (Thermo Fisher, Waltham, MA, USA) after the dissolution of the metals in aqua regia.

Optical images of were collected on digital USB microscope (RS Pro, Fort Worth, TX, USA). The samples were supported on a microscopic glass and imaged without a glass cover.

Catalysts were characterized by FEI transmission electron microscopy (TEM) with the electron microscope Titan G2 60-300 kV (FEI company, Tokyo, Japan) equipped with EDAX EDS (energy-dispersive X-ray spectroscopy) detector. Microscopic studies of the catalysts were carried out at an accelerating voltage of the electron beam equal to $300 \mathrm{kV}$. The samples were prepared by dispersing the catalysts in ethanol and sonication until clear solutions were obtained. The TEM specimen consisted of a drop of the prepared suspensions on carbon films on copper grids.

Powder X-ray diffraction (PXRD) measurements were performed in a X-Ray Diffractometer D5000 (Siemens, Munich, Germany) employing Bragg-Brentano configuration. This type of arrangement was provided using PANalytical Empyrean diffraction platform (Malvern, Germnay), powered at $40 \mathrm{kV} \times 40 \mathrm{~mA}$ and equipped with a vertical goniometer, with theta-theta geometry using Ni filtered $\mathrm{Cu} \mathrm{K} \alpha$ radiation. Data were collected in the range of $2 \theta=5-95^{\circ}$, with a step size of $0.008^{\circ}$ and counting time 60 s/step.

X-ray absorption spectroscopy (XAS) measurements were performed in air in a home built laboratory X-ray setup [63]. The setup uses a von Hamos geometry-based detection system. The source 
was XOS X-Beam Superflux PF X-ray tube (XOS, New York, NY, USA) operated at the voltage of $40 \mathrm{kV}$ and the current of $0.9 \mathrm{~mA}$. The photon beam left the X-ray tube through an integrated focusing optics at about $3^{\circ}$ divergence and illuminated the sample. The sample position was fixed at the beam focal point with the nominal beam spot size of about $100 \mu \mathrm{m}$. The radiation transmitted through the target was diffracted by a cylindrically bent $\mathrm{Si}(440)$ crystal with $25 \mathrm{~cm}$-radius of curvature at the Bragg angle of $65.2^{\circ}$ and registered by an Andor Newton CCD camera (Oxford Instruments, Abingdon, UK) sealed with $250 \mu \mathrm{m}$-thick Be window. The camera's CCD chip, a front-illuminated sensor composed of $1024 \times 256$ with $26 \mu \mathrm{m}$-sized pixels, was operated at the pressure of about $10^{-7} \mathrm{mbar}$ and the temperature of $-40{ }^{\circ} \mathrm{C}$ controlled by a thermoelectric cooler built-in device.

The chemical surface composition of the series of Ni-Pd catalysts was characterized by the XPS spectroscopy using a Microlab 350 spectrometer (Thermo Electron, Abingdon, Germany). XPS spectra were excited using $\mathrm{Al}_{\mathrm{K} \alpha}(\mathrm{h} v=1486.6 \mathrm{eV}, 300 \mathrm{~W})$ radiation as a source. Survey spectra and also high-resolution spectra were recorded using 100 and $40 \mathrm{eV}$ pass energy, respectively. A linear or Shirley background subtraction was made to obtain XPS signal intensity. The peaks were fitted using an asymmetric Gaussian/Lorentzian mixed function. The measured binding energies were revised referring to the energy of $\mathrm{C} 1 \mathrm{~s}$ at $285.0 \mathrm{eV}$. For data processing was used an Avantage software version 4.88 (Thermo Fisher, Waltham, MA, USA).

\subsection{6-Methyl-5-Hepten-2-One Hydrogenation}

Hydrogenation reactions were conducted using commercial high-pressure micro-reactor $\mathrm{H}$-Cube Pro equipment from Thales Nano (Thales Nano, Hungary) with built in $\mathrm{H}_{2}$ generator (by water electrolysis). Deuterium experiments were performed by using $\mathrm{D}_{2} \mathrm{O}$ instead of $\mathrm{H}_{2} \mathrm{O}$ electrolysis. The mixture of $0.05 \mathrm{M}$ 6-methyl-5-hepten-2-on in ethanol was continuously injected to the system using an HPLC pump and it flowed through the disposable cartridge CatCart70 with an ID of $4 \mathrm{~mm}$ where was preloaded required $0.15 \mathrm{~g}$ monometallic or bimetallic catalyst. To determine the optimal reaction parameters, in every case was performed screening reaction with a wide range of temperatures $\left(25-100^{\circ} \mathrm{C}\right)$ and pressures $(10-60$ bar) with reactant flow rate $0.5 \mathrm{~mL} / \mathrm{min}(25 \mathrm{~mol} / \mathrm{min})$. After that, 5-h hydrogenation reactions were conducted with previously experimentally determined the best reaction parameters. The reported activity and selectivity values were extracted after reaching steady-state performance, normally within 25-30 min of operation. Time zero in every reaction was stipulated to be $3 \mathrm{~min}$ of after starting the substrate solution flow as this is the estimated residence time of a solution in the reactor at a flow rate of $0.5 \mathrm{~mL} / \mathrm{min}$. The reaction progress and concentrations of the products were verified by gas chromatography (GC), i.e., Bruker 456 GC (Bruker, Bremen, Germnay) equipped with FID detector and non-polar BP-5 $0.25 \mu \mathrm{m}$ (5\% phenyl, $95 \%$ dimethyl polysiloxane) column.

Note that the gas pressure and flow in the reactor are monitored continuously, and thus providing a direct measurement of the amount of gas present in the system. Additionally, the experiments were performed only after equilibration of the system, meaning reactions were performed after reaching stable gas pressure and flow. Finally, the electrolysis cell produces excess gas to avoid instabilities in the system throughout the reaction. This ensures that KIE results due to the parent catalyst abilities, not experimental limitations.

\subsection{Quantum Chemical Calculations}

Set-up for the density functional theory (DFT) calculations was described in great details in our previous works on Ni-Sn [34] and Ni-Zr [35] systems. Briefly, the final reported energies for icosahedral $\mathrm{Ni}_{13}, \mathrm{Ni}_{13} \mathrm{Pd}$, and $\mathrm{Pd}_{13}$ model nanoparticles were computed with the PBE functional [64] augmented with D3BJ dispersion correction $[65,66]$ along with the def2-TZVP basis set [67] at the multiplicity of 9. Zero-point energies were obtained after numerical frequency run. ORCA 4.2.0 program [68] was used for all DFT computations. In this work, however, we used a different method to generate the initial candidates for the lowest energy structures due to multiple possible configurations 
of $\mathrm{H}_{2}$ and $\mathrm{H}$ atoms adsorbed at the nanoparticle models. Here, the pre-optimization was performed using the extended tight binding method (GFN2-xTB) of Grimme et al. [69] using their stand-alone code. Fermi smearing $(300 \mathrm{~K})$ of the orbital occupation numbers was applied to ensure proper electronic structure convergence. Molecular dynamics simulations at 100 ps was run to confirm stability of obtained structures. In all cases, end-on $\mathrm{H}_{2}$ binding mode was obtained and $\mathrm{H}$ atoms were decorating the nanoparticles. The obtained structures were then used as the starting point for DFT computations. $\mathrm{XYZ}$ coordinates of key structures are reported in the Supplementary Materials.

\section{Conclusions}

Herein, it is demonstrated that nickel catalyst activity in the liquid-phase high-pressure chemoselective hydrogenation of an unsaturated ketone can be significantly increased by the addition of sub-catalytic amounts of palladium. The doping did not affect the catalyst selectivity to double bond saturation and stability, revealing that palladium function is to improve the activation of hydrogen on the catalyst surface, which was found to be the rate-limiting step by kinetic isotopic explements and DFT calculations. The modification was found so effective that the doped Ni catalyst activity exceeded its Pd monometallic counterpart under optimal conditions, using 10 times less palladium and about 2 times less metal. The observation suggests a synergetic effect between the two metals, namely that palladium activates hydrogen and spills it over to the nickel surface [70] where the reactant is reduced faster than on a Pd counterpart possible due to selective absorption of the substrate. The approach can be exploited to develop low costs and specific catalysts for flow hydrogenation processes in the liquid phase.

Supplementary Materials: The following are available online at http://www.mdpi.com/2073-4344/10/11/1267/s1, Figure S1: Diffraction patterns of the polymeric support with and without Ni NPs. Figure S2. FTIR of the $-\mathrm{NH}_{2}$ vibrational regions depicting the drop in their intensity due to binding of Ni nanoparticles. Figure S3: NMR spectrum of 6-methyl-5-hepten-2-one (substrate). Figure S4: NMR spectrum of 6-methyl-2-heptanone (product) after substrate deuteration. Table S1: Ni and Pd content for $\mathrm{NiPd}_{0.22} \mathrm{TSNH}_{2}$. Figure S5: STEM images and elemental mapping for $\mathrm{NiPd}_{0.22} \mathrm{TSNH}_{2}$. Figure S6: HRTEM image for $\mathrm{NiPd}_{0.22} \mathrm{TSNH}_{2}$. Figure S7: Screening of the $\mathrm{NiPd}_{0.05} \mathrm{TSNH}_{2}$ activity under various temperatures and pressures in unsaturated ketone hydrogenation. Figure S8: Screening of the $\mathrm{NiPd}_{0.13} \mathrm{TSNH}_{2}$ activity under various temperatures and pressures in unsaturated ketone hydrogenation. Figure S9: Comparative study showing the effect of Pd loading in the overall product formation. Table S1: Ni and Pd content for $\mathrm{NiPd}_{0.22} \mathrm{TSNH}_{2}$. Table S2: XYZ coordinates.

Author Contributions: Conceptualization, J.S. (Jacinto Sá); Data curation, I.G.; Formal analysis, I.G., M.Z.-M., W.B., A.K., D.G., K.M., K.N., D.L., A.Ś. and J.S. (Jakub Szlachetko); Investigation, I.G., M.Z.-M., W.B., A.K., K.M., K.N. and D.L.; Methodology, A.K., K.M. and J.S. (Jacinto Sá); Project administration, I.G. and A.Ś.; Resources, J.S. (Jacinto Sá); Supervision, A.Ś. and J.S. (Jacinto Sá); Writing—original draft, J.S. (Jacinto Sá); Writing-review \& editing, I.G., A.S. and J.S. (Jakub Szlachetko). All authors have read and agreed to the published version of the manuscript.

Funding: This research was funded by the Polish National Science Center NCN-OPUS 8 grant no. UMO-2014/15/BST5/02094 and the Polish Ministry of Science and Higher Education IDEAS Plus II IdPII 2015000164.

Acknowledgments: This work was partially supported by a grant from the National Science Center in Poland (OPUS 8, grant no. UMO-2014/15/B/ST5/02094) and the Polish Ministry of Science and Higher Education (IDEAS Plus II IdPII 2015000164). A.K. acknowledges support from the National Science Center, Poland, grant number 2018/30/E/ST4/00004. Access to high-performance computing resources was provided by the Interdisciplinary Center for Mathematical and Computational Modelling in Warsaw, Poland, under grant no. GB77-11.

Conflicts of Interest: The authors declare no conflict of interest.

\section{References}

1. Ranade, V.V.; Joshi, S.S. Industrial Catalytic Processes for Fine and Specialty Chemicals; Elsevier: Amsterdam, The Netherlands, 2016; pp. 1-14.

2. Weissermel, K.; Arpe, H.J. Industrial Organic Chemistry; Verlag Chemie: Weinheim, Germany, 1978. 
3. Bonrath, W.; Medlock, J.; Schütz, J.; Wüstenberg, B.; Netscher, T. Hydrogenation in the Vitamins and Fine Chemicals Industry - An Overview; Intechopen: London, UK, 2012.

4. Royo, B. Sustainable Synthesis of Pharmaceuticals: Using Transition Metal Complexes as Catalysts; RSC: London, UK, 2018.

5. Bauer, K.; Garbe, D. Ullman Encyclopedia; VCH: New York, NY, USA, 1988; p. 141.

6. Gallezot, P.; Richard, D. Selective hydrogenation of $\alpha, \beta$-unsaturated aldehydes. Catal. Rev. Sci. Eng. 1998, 40, 81-126. [CrossRef]

7. Righi, G.; Rossi, L. Mild regioselective catalytic hydrogenation of $\alpha, \beta$-unsaturated carbonyl compounds with lindlar catalyst. Syth. Commun. 1996, 26, 1321-1327. [CrossRef]

8. Bauer, K.; Garbe, D.; Surburg, H. Common Fragrance and Flavour Materials: Preparation, Properties and Uses, 3rd ed.; Wiley-VCH: Weinheim, Germany, 1977.

9. Grolig, J. Ullmann's Encyclopedia of Industrial Chemistry, 7th ed.; Wiley-VCH: Weinheim, Germany, 2003.

10. Siddqui, N.; Sarkar, B.; Pendem, C.; Khatum, R.; Konthala, L.N.S.; Sasaki, T.; Bordoloi, A.; Bal, R. Highly selective transfer hydrogenation of $\alpha, \beta$-unsaturated carbonyl compounds using Cu-based nanocatalysts. Catal. Sci. Technol. 2017, 7, 2828-2837. [CrossRef]

11. Farrar-Tobar, R.A.; Tin, S.; de Vries, J.G. Organometallics for Green Chemistry; Springer: Berlin/Heidelberg, Germany, 2018; pp. 193-224.

12. Mendes-Burak, J.; Ghaffari, B.; Copéret, C. Selective hydrogenation of $\alpha, \beta$-unsaturated carbonyl compounds on silica-supported copper nanoparticles. Chem. Commun. 2019, 55, 179-181. [CrossRef] [PubMed]

13. Bonrath, W.; Netscher, T. Catalytic processes in vitamins synthesis and production. Appl. Catal. A Gen. 2005, 280, 55-73. [CrossRef]

14. Wang, X.; He, Y.; Liu, Y.; Park, J.; Liang, X. Atomic layer deposited Pt-Co bimetallic catalysts for selective hydrogenation of $\alpha, \beta$-unsaturated aldehydes to unsaturated alcohols. J. Catal. 2018, 366, 61-69. [CrossRef]

15. Du, W.Q.; Rong, Z.M.; Liang, Y.; Wang, Y.; Lu, X.Y.; Wang, Y.F.; Lu, L.H. Chemoselective hydrogenation of $\alpha, \beta$-unsaturated aldehydes with modified Pd/C catalyst. Chin. Chem. Lett. 2012, 23, 773-776. [CrossRef]

16. Goszewska, I.; Giziński, D.; Zienkiewicz-Machnik, M.; Lisovytskiy, D.; Nikiforov, K.; Masternak, J.; Śręowata, A.; Sá, J. A novel nano-palladium catalyst for continuous-flow chemoselective hydrogenation reactions. Catal. Commun. 2017, 94, 65-68. [CrossRef]

17. Tessonnier, J.-P.; Pesanat, L.; Ehret, G.; Ledoux, M.J.; Pham-Huu, C. Pd nanoparticles introduced inside multi-walled carbon nanotubes for selective hydrogenation of cinnamaldehyde into hydrocinnamaldehyde. Appl. Catal. A Gen. 2005, 288, 203-210. [CrossRef]

18. Banerjee, S.; Balasanthiran, V.; Koodali, R.T.; Sereda, G.A. Pd-MCM-48: A novel recyclable heterogeneous catalyst for chemo- and regioselective hydrogenation of olefins and coupling reactions. Org. Biomol. Chem. 2010, 8, 4316-4321. [CrossRef]

19. Coloma, F.; Sepúlveda-Escribano, A.; Fierro, J.L.G.; Rodriguez-Reinoso, F. Crotonaldehyde hydrogenation over bimetallic Pt-Sn catalysts supported on pregraphitized carbon black. Effect of the Sn/Pt atomic ratio. Appl. Catal. A Gen. 1996, 136, 231-248. [CrossRef]

20. Mahata, N.; Goncalves, F.; Fernando, M.; Pereira, R.; Figueiredo, J.L. Selective hydrogenation of cinnamaldehyde to cinnamyl alcohol over mesoporous carbon supported Fe and Zn promoted Pt catalyst. Appl. Catal. A Gen. 2008, 339, 159-168. [CrossRef]

21. Hu, C.; Creaser, D.; Siahrostami, S.; Grönbeck, H.; Ojagh, H.; Skoglundh, M. Catalytic hydrogenation of C = $\mathrm{C}$ and $\mathrm{C}=\mathrm{O}$ in unsaturated fatty acid methyl esters. Catal. Sci. Technol. 2014, 4, 2427-2444. [CrossRef]

22. Murillo, L.E.; Menning, C.A.; Chen, J.G. Trend in the $\mathrm{C}=\mathrm{C}$ and $\mathrm{C}=\mathrm{O}$ bond hydrogenation of acrolein on $\mathrm{Pt}-\mathrm{M}(\mathrm{M}=\mathrm{Ni}, \mathrm{Co}, \mathrm{Cu})$ bimetallic surfaces. J. Catal. 2009, 268, 335-342. [CrossRef]

23. Hudson, R.; Hamasaka, G.; Osako, T.; Yamada, Y.M.A.; Li, C.-J.; Uozumi, Y.; Moores, A. Highly efficient iron(0) nanoparticle-catalyzed hydrogenation in water in flow. Green Chem. 2013, 15, 2141-2148. [CrossRef]

24. Wang, Y.; Qin, R.; Wang, Y.; Ren, J.; Zhou, W.; Li, L.; Ming, J.; Zhang, W.; Fu, G.; Zheng, N. Chemoselective hydrogenation of nitroaromatics at the nanoscale iron(III)-OH-platinum interface. Angew. Chem. Int. Ed. 2020, 59, 12736-12740. [CrossRef] 
25. Gong, X.; Wang, M.; Fang, H.; Qian, X.; Ye, L.; Duan, X.; Yuan, Y. Copper nanoparticles socketed in situ into copper phyllosilicate nanotubes with enhanced performance for chemoselective hydrogenation of esters. Chem. Commun. 2017, 53, 6933-6936. [CrossRef]

26. Xavier, K.O.; Sreeekala, R.; Rashid, K.K.A.; Yusuff, K.K.M.; Sen, D. Doping effects of cerium oxide on $\mathrm{Ni} / \mathrm{Al}_{2} \mathrm{O}_{3}$ catalysts for methanation. Catal. Today 1999, 49, 17-21. [CrossRef]

27. Hauptmann, H.; Walter, W.F. The action of raney nickel on organic sulfur compounds. Chem. Rev. 1962, 62, 347-404. [CrossRef]

28. Alonso, F.; Riente, P.; Yus, M. Nickel nanoparticles in hydrogen transfer reactions. Acc. Chem. Res. 2011, 44, 379-391. [CrossRef]

29. Qi, S.-C.; Zhang, L.; Einaga, H.; Kudo, S.; Norinaga, K.; Hayashi, J.-I. Nano-sized nickel catalyst for deep hydrogenation of lignin monomers and first-principles insight into the catalyst preparation. J. Mater. Chem. A 2017, 5, 3948-3965. [CrossRef]

30. Jiang, Z.; Xe, J.; Jiang, D.; Wei, X.; Chen, M. Modifiers-assisted formation of nickel nanoparticles and their catalytic application to p-nitrophenol reduction. CrystEngComm 2013, 15, 560-569. [CrossRef]

31. Kishida, S.; Murakami, Y.; Imanaka, T.; Teranishi, S. Hydrogenation of various ketones on nickel boride catalyst. J. Catal. 1968, 12, 97-101. [CrossRef]

32. Giziński, D.; Błachucki, W.; Śrębowata, A.; Zienkiewcz-Machnik, M.; Goszewska, I.; Matus, K.; Lisovytskiy, D.; Pisarek, M.; Szlachetko, J.; Sá, J. On-the-fly catalyst accretion and screening in chemoselective flow hydrogenation. ChemCatChem 2018, 10, 3641-3646. [CrossRef]

33. Budroni, G.; Kondrat, S.A.; Taylor, S.H.; Morgan, D.J.; Carley, A.F.; Williams, P.B.; Hutchings, G.J. Selective deposition of palladium onto supported nickel-bimetallic catalysts for the hydrogenation of crotonaldehyde. Catal. Sci. Technol. 2013, 3, 2746-2754. [CrossRef]

34. Hammoudeh, A.; Mahmoud, S. Selective hydrogenation of cinnamaldehyde over $\mathrm{Pd} / \mathrm{SiO}_{2}$ catalysts: Selectivity promotion by alloyed Sn. J. Mol. Catal. A Chem. 2003, 203, 231-239. [CrossRef]

35. Fulajtárova, K.; Sotác, T.; Hronec, M.; Vávra, I.; Dobročka, E.; Omastová, M. Aqueous phase hydrogenation of furfural to furfuryl alcohol over Pd-Cu catalysts. Appl. Catal. A Gen. 2015, 502, 78-85. [CrossRef]

36. Mo, M.; Xie, M.; Guo, X.; Ding, W.; Guo, X. The promoted catalytic hydrogenation performance of bimetallic $\mathrm{Ni}-\mathrm{Co}-\mathrm{B}$ noncrystalline alloy nanotubes. RSC Adv. 2019, 9, 26456-26463. [CrossRef]

37. Nakagawa, Y.; Tomishige, K. Total hydrogenation of furan derivatives over silica-supported Ni-Pd alloy catalyst. Catal. Commun. 2010, 12, 154-156. [CrossRef]

38. Tan, L.; Li, T.; Zhou, J.; Chen, H.; Jiang, F. Liquid-phase hydrogenation of N-nitrosodimethylamine over Pd-Ni supported on CeO2-TiO2: The role of oxygen vacancies. Coll. Surf. A 2018, 558, 211-218. [CrossRef]

39. McAllister, M.I.; Boulho, C.; Gilpin, L.F.; McMillan, L.; Brennan, C.; Lenon, D. Hydrogenation of benzonitrile over supported pd catalysts: Kinetic and mechanistic insight. Org. Process Res. Dev. 2019, 23, 977-989. [CrossRef]

40. Liguori, F.; Barbaro, P.; Sawa, H. Continuous flow hydrogenation reactions by Pd catalysts onto hybrid ZrO2/PVA materials. Appl. Catal. A Gen. 2014, 488, 58-65. [CrossRef]

41. Sá, J.; Medlin, J.W. On-the-fly catalyst modification: Strategy to improve catalytic processes selectivity and understanding. ChemCatChem 2019, 11, 3355-3365. [CrossRef]

42. Cossar, P.J.; Hizartzidis, L.; Simone, M.I.; McCluskey, A.; Gordon, C.P. The expanding utility of continuous flow hydrogenation. Org. Biomol. Chem. 2015, 13, 7119-7130. [CrossRef]

43. Mallia, C.J.; Baxendale, I.R. The use of gases in flow synthesis. Org. Process Res. Dev. 2016, 20, 327-360. [CrossRef]

44. Jones, R.V.; Godorhazy, L.; Varga, N.; Szalay, D.; Urge, L.; Darvas, F. Continuous-flow high pressure hydrogenation reactor for optimization and high-throughput synthesis. J. Comb. Chem. 2006, 8, 110-116. [CrossRef]

45. Zienkiewicz-Machnik, M.; Goszewska, I.; Śrębowata, A.; Kubas, A.; Giziński, D.; Słowik, G.; Matus, K.; Lisovytskiy, D.; Pisarek, M.; Sá, J. Tuning nano-nickel selectivity with tin in flow hydrogenation of 6-methyl-5-hepten-2-one by surface organometallic chemistry modification. Catal. Today 2018, 308, 38-44. [CrossRef] 
46. Zienkiewcz-Machnik, M.; Goszewska, I.; Giziński, D.; Śrębowata, A.; Kuzmowicz, K.; Kubas, A.; Matus, K.; Lisovytskiy, D.; Pisarek, M.; Sá, J. Tuning nano-nickel catalyst hydrogenation aptitude by on-the-fly zirconium doping. Chem CatChem 2020, 12, 3132-3138. [CrossRef]

47. Ayats, C.; Henseler, A.H.; Pericas, M.A. A solid-supported organocatalyst for continuous-flow enantioselective aldol reactions. ChemSusChem 2012, 5, 320-325. [CrossRef]

48. Canellas, S.; Ayats, C.; Henseler, A.H.; Pericas, M.A. A highly active polymer-supported catalyst for asymmetric robinson annulations in continuous Flow. ACS Catal. 2017, 7, 1383-1391. [CrossRef]

49. Krill, S.; Huthmacher, K. Process for the production of 6-methyl heptanone. Patent No. US6417406B1, 10 September 2001.

50. Giziński, D.; Goszewska, I.; Zieliński, M.; Lisovytskiy, D.; Nikiforov, K.; Masternak, J.; Zienkiewcz-Machnik, M.; Śrębowata, A.; Sá, J. Chemoselective flow hydrogenation of $\alpha, \beta$-Unsaturated aldehyde with nano-nickel. Catal. Commun. 2017, 98, 17-21. [CrossRef]

51. Quaino, P.; Juarez, F.; Santos, E.; Schmickler, W. Volcano plots in hydrogen electrocatalysis-Uses and abuses. Beilstein J. Nanotechnol. 2014, 5, 846-854. [CrossRef] [PubMed]

52. Laursen, A.B.; Varela, A.S.; Dionigi, F.; Fanchiu, H.; Miller, C.; Trinhammer, O.L.; Rossmeisl, J.; Dahl, S. Electrochemical hydrogen evolution: Sabatier's principle and the volcano plot. J. Chem. Educ. 2012, 89, 1595-1599. [CrossRef]

53. Van Meerten, R.; Morales, A.; Barbier, J.; Maurel, R. Isotope effects in the hydrogenation and exchange of benzene on platinum and nickel. J. Catal. 1979, 58, 43-51. [CrossRef]

54. Adams, B.D.; Chen, A. The role of palladium in a hydrogen economy. Mater. Today 2011, 14, 282-289. [CrossRef]

55. Pan, D.; Jian, J.K.; Ablat, A.; Li, J.; Sun, Y.F.; Wu, R. Structure and magnetic properties of Ni-doped AlN films. J. Appl. Phys. 2012, 112, 053911. [CrossRef]

56. Pulm, H.; Hohlneicher, G.; Freund, H.-J.; Schuster, H.-U.; Drews, J.; Eberv, U. Charge distribution in some ternary vintl phases as studied by v-ray photoelectron spectroscopy. J. Less Common Met. 1986, 115, 127-143. [CrossRef]

57. Kumar, G.; Blackburn, J.R.; Albridge, R.G.; Moddeman, W.E.; Jones, M.M. Photoelectron spectroscopy of coordination compounds. II. Palladium complexes. Inorg. Chem. 1972, 11, 296-300. [CrossRef]

58. Vogt, C.; Groeneveld, E.; Kamsma, G.; Nachtegaal, M.; Lu, L.; Kiely, C.J.; Berben, P.H.; Meirer, F.; Weckhuysen, B.M. Unravelling structure sensitivity in CO2 hydrogenation over nickel. Nat. Catal. 2018, 1, 127-134. [CrossRef]

59. Barbier, J. Handbook of Heterogeneous Catalysis; Ertl, G., Knözinger, H., Weitkamp, J., Eds.; Wiley: Weinheim, Germany, 1997; p. 257.

60. Epron, F.; Gauthard, F.; Pinéda, C.; Barbier, J. Catalytic reduction of nitrate and nitrite on Pt-Cu/Al2O3 catalysts in aqueous solution: Role of the interaction between copper and platinum in the reaction. J. Catal. 2001, 198, 309-318. [CrossRef]

61. Sá, J.; Vinek, H. Catalytic hydrogenation of nitrates in water over a bimetallic catalyst. Appl. Catal. B Environ. 2005, 57, 247-256. [CrossRef]

62. Sá, J.; Gross, S.; Vinek, H. Effect of the reducing step on the properties of Pd-Cu bimetallic catalysts used for denitration. Appl. Catal. A Gen. 2005, 294, 226-234. [CrossRef]

63. Błachucki, W.; Czapla-Masztafiak, J.; Sá, J.; Szlachetko, J. A laboratory-based double X-ray spectrometer for simultaneous X-ray emission and X-ray absorption studies. J. Anal. At. Spectrom. 2019, 34, 1409-1415 [CrossRef]

64. Perdew, J.P.; Burke, K.; Ernzerhof, M. Generalized gradient approximation made simple. Phys. Rev. Lett. 1996, 77, 3865-3868. [CrossRef] [PubMed]

65. Grimme, S.; Antony, J.; Ehrlich, S.; Krieg, H. A consistent and accurate ab initio parametrization of density functional dispersion correction (DFT-D) for the 94 elements H-Pu. J. Chem. Phys. 2010, 132, 154104-154119. [CrossRef]

66. Grimme, S.; Ehrlich, S.; Goerigk, L. Effect of the damping function in dispersion corrected density functional theory. J. Comput. Chem. 2011, 32, 1456-1465. [CrossRef]

67. Weigend, F. Accurate coulomb-fitting basis sets for $\mathrm{H}$ to Rn. Phys. Chem. Chem. Phys. 2006, 8, 1057-1065. [CrossRef]

68. Neese, F. Software update: The ORCA program system, version 4.0. Wiley Interdiscip. Rev. Comput. Mol. Sci. 2017, 8, e1327. [CrossRef] 
69. Bannwarth, C.; Ehlert, S.; Grimme, S. GFN2-xTB-An accurate and broadly parametrized self-consistent tight-binding quantum chemical method with multipole electrostatics and density-dependent dispersion contributions. J. Chem. Theory Comput. 2019, 15, 1652-1671. [CrossRef]

70. Prins, R. Hydrogen spillover. Facts and fiction. Chem. Rev. 2012, 112, 2714-2738. [CrossRef]

Publisher's Note: MDPI stays neutral with regard to jurisdictional claims in published maps and institutional affiliations.

(C) 2020 by the authors. Licensee MDPI, Basel, Switzerland. This article is an open access article distributed under the terms and conditions of the Creative Commons Attribution (CC BY) license (http://creativecommons.org/licenses/by/4.0/). 